\title{
A DESCRIPTIVE STUDY ANALYSING THE PERFORMANCE OF TYPICALLY DEVELOPING INDIAN CHILDREN ON MOTOR FREE VISUAL PERCEPTUAL TEST-4 (MVPT-4)
}

\author{
Dr. Sheetal Gupta ${ }^{1}$, Dr. Anita Gupta ${ }^{2}$, Dr. Sushmita Ahirwal ${ }^{3}$ \\ ${ }^{1}$ Clinical Occupational Therapist
}

Article DOI: https://doi.org/10.36713/epra8165

DOI No: 10.36713/epra8165

ABSTRACT
Visual perception is the process by which individuals assign meaning, understanding, and interpretation to what
they have seen. The aim of this study was to determine the visual perceptual skills of typically developing Indian
children on MVPT-4. A sample of 180 typically developing Indian students were included in the study using
convenience sampling method. They were divided in six age groups with age ranging from 6years to 12 years with
30 children in each age group. It was found that visual perceptual skills of typically developing Indian children in
6-12 years of age group can be assessed using MVPT-4. Analysis was done using One-way Anova to compare the
mean raw score of each age group. There was a significant difference between the age groups at statistical value of
p<0.001. The score improved with age, signifying refined and matured visual perceptual skills in older children.
Age influences visual-perceptual skills of these children. This study also provides a foundation for further
researches and highlights the importance of MVPT-4 as a screening tool to be used by the occupational therapist in
order to assess the visual perceptual skills of children.

\section{INTRODUCTION}

Perception is a mental level existing between sensation and cognition ${ }^{(1)}$. Visual perceptual skills include the recognition and identification of shapes, objects, colours, and other qualities. The relationship between visual-perceptual abilities and function in everyday activities is subtle but all-encompassing ${ }^{(2)}$. Students spend $30 \%$ to $60 \%$ of their school day on sustained reading, writing, and other desktop tasks utilizing vision (McHale \& Cermak, 1992; Ritty, Solan, \& Cool, 1993) ${ }^{(3)}$. If the child has difficulties in visual performance it may lead to difficulties with academic performance, attention and concentration, self-regulation, behaviour, avoidance ${ }^{(4)}$.

To identify visual perceptual factors that limit occupational performance and participation, occupational therapist often ask and observe how visual perceptual difficulties affect daily occupations by using top-down approach ${ }^{(5)}$. These skills are assessed, in one form or another, by the tests of visual perception. Scales like Test of Visual Perceptual Skills, Developmental Test of Visual
Perception, Motor-Free Visual Perceptual Test, Test of Pictures, Forms, Letters, Numbers, Spatial Orientation and Sequencing Skills, Miller Assessment for Pre-schooler's are widely used for same ${ }^{(6)}$. In this study, Motor-Free Visual Perceptual Test, Fourth Edition (MVPT-4) is used to assess the visual-perceptual skills of Indian children.

MVPT-4 is a recently modified version of MVPT-3 which has 45 items ${ }^{(6)}$. There are no researches available on MVPT-4 for Indian population and also limited research articles are available on MVPT-4 worldwide. This study will provide a foundation for further researches and will also highlight the importance of MVPT-4 as a screening device to be used by the therapist in order to assess the visual perceptual skills of the children The study was conducted to determine the visual perceptual skills of typically developing Indian children on MVPT-4. 


\section{EPRA International Journal of Research and Development (IJRD)}

\section{METHODOLOGY}

A prospective, descriptive, cross-sectional study was conducted using MVPT-4. A sample of 180 participants were recruited for the study. Convenience sampling technique was used. A period of 18 months was needed to complete the data collection. Children between 6-12 years of age, having ability to comprehend instructions, with normal or corrected vision and having willingness to participate in the study were included. Children who had history of Head trauma in the past or any other visual problem (e.g. field defects), or any other apparent neurological or orthopaedic condition interfering with visual perception skills were excluded from the study.

Study procedure-

After obtaining the approval from the ethics committee of the institute, the study was conducted on selected children. Demographic information was collected for each child to gather relevant background data and confirming inclusion criteria. The child's performance of visual perceptual skills was assessed using MVPT-4. Each child was assessed by the therapist on one-on-one basis. Care was taken to keep child away from any distraction. Therapist instructed the child as per the instructions given for each test item. Child was allowed to give response for each test plate irrespective of the time taken. Therapist marked the child's response on a response sheet. No feedback was given to the child about his response. Total 45 test plates were administered which included testing visual memory, visual discrimination, visual closure, figure ground discrimination and form constancy. The session comprised of 30-40 minutes approximately.

Table 1: Age wise distribution of raw score with mean and SD of typically developing Indian children.

\begin{tabular}{|c|c|c|c|}
\hline Age group & $\mathbf{N}$ & Raw score & Standard score \\
\hline $6-7$ yrs. & 30 & $24.4+3.7(14-31)$ & $103.4+9.2(79-120)$ \\
\hline $7-8$ yrs. & 30 & $26.7+3.1(21-33)$ & $103.2+9.4(80-120)$ \\
\hline $8-9$ yrs. & 30 & $30.2+4.1(22-38)$ & $109.1+12.1(86-138)$ \\
\hline $9-10$ yrs. & 30 & $31.4+3.7(21-41)$ & $108.4+10.9(84-144)$ \\
\hline $10-11$ yrs. & 30 & $33.4+3.9(22-40)$ & $108.5+11.1(79-132)$ \\
\hline $11-12$ yrs. & 30 & $34.3+3.6(27-42)$ & $108.6+11.0(89-137)$ \\
\hline Total & 180 & $30.1+5.1(14-42)$ & $106.9+10.8(79-144)$ \\
\hline
\end{tabular}

The study was concluded after gathering data of 180 children. The gathered data was taken for further statistical analysis.

\section{Motor Free Visual Perceptual Test-4:}

The MVPT-4 is the latest updated test by Ronald P. Colarusso, EdD, and Donald D. Hammill, EdD in 2015. Since first published in 1972, the MVPT assesses person's overall visual-perceptual ability in a format that is not dependent on motor skills in persons aged 4-0 through 80+ years using a variety of types of visual-perceptual tasks ${ }^{(6)}$. It has 45 items, retained from MVPT-3. The reduced number of items in the MVPT-4 shortens the administration me slightly but maintains the increased cognitive load. The 45 items are arranged in five sections, each having nine items plus one unscored sample items that can be used to teach the tasks. Items have a itiple-choice format, yielding one overall raw RESULTS

The data was entered using MS-Excel-2007 and analysed using SPSS-16 software. Descriptive analysis for numerical data consists of mean with standard deviation (SD) and the categorical data consists of frequencies \& percentage for various wh with Bonferroni test - which is used for post hoc comparison. The $p$ value less than 0.05 was taken as statistically significant. 


\section{EPRA International Journal of Research and Development (IJRD)}

Volume: 6 | Issue: 9 | September 2021

- Peer Reviewed Journal

Figure 1: Distribution of typically developing children in each age groups and mean score (raw score and standard score) performance of MVPT-4.

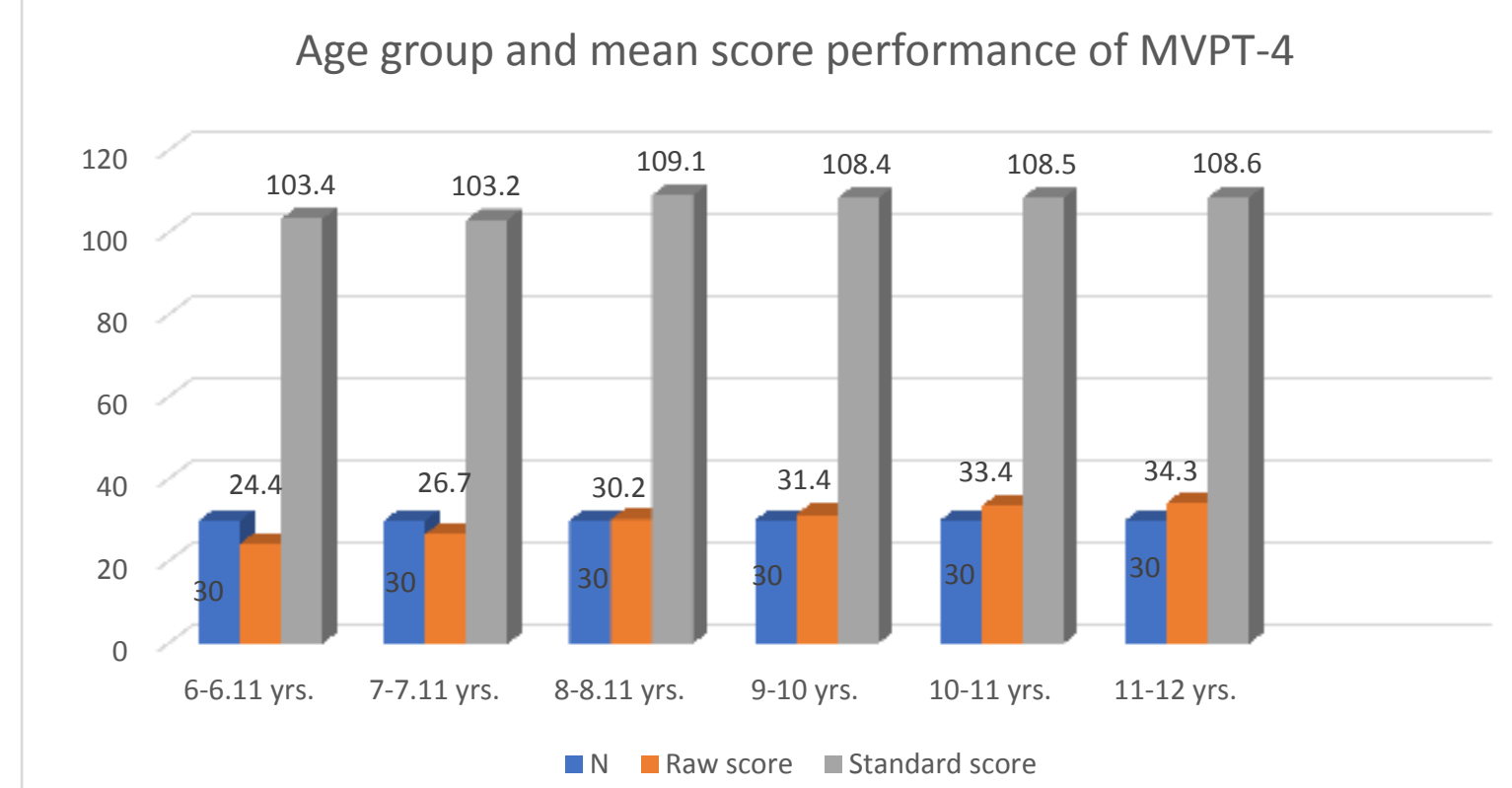

The data was divided into 6 groups ranging from the age 6yrs to 12 years. Each age groups had 30 participants (16.67\% of total population). The mean age of the study participants was 8.5 years with a standard deviation of 1.7 years. Overall Visual perceptual skills score was calculated for all the age groups and raw score was $30.1+5.1(14-42)$ and standard score $106.9+10.8(79-144)$. The mean of raw score ranged between 24.4 to 34.3 for all the age groups. The standard score ranged from 103.2 to 109.1 for all the age group. The mean standard score for 6-7 year was $103.4+9.2(79-120)$, 7-8year was $103.2+9.4(80-120), 8-9$ years was $109.1+12.1(86-$ $138), 9-10$ years was $108.4+10.9(84-144), 10-11$ years was $108.5+11.1(79-132)$ and $11-12$ years was $108.6+11.0(89-137)$ respectively.

Table 2: Distribution of Visual Perceptual skill scores.

\begin{tabular}{|c|c|c|}
\hline Visual perceptual deficits & Frequency & Percent \\
\hline Standard scores $<100$ & 35 & 19.4 \\
\hline Standard scores $>100$ & 145 & 80.6 \\
\hline Total & $\mathbf{1 8 0}$ & $\mathbf{1 0 0 . 0}$ \\
\hline
\end{tabular}

Figure 2: Distribution of Visual Perceptual skill scores.

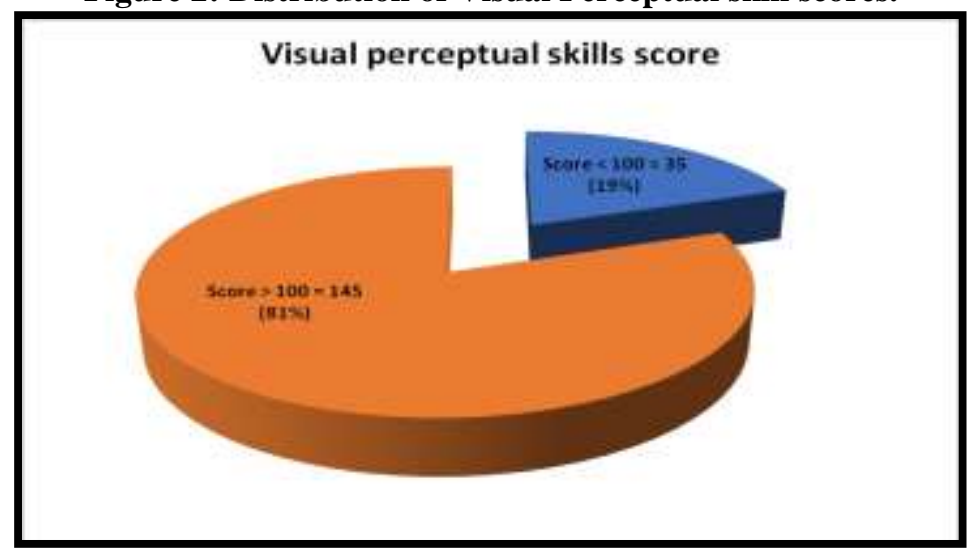




\section{EPRA International Journal of Research and Development (IJRD)}

Volume: 6 | Issue: 9 | September 2021

- Peer Reviewed Journal

It is observed from the above table that 35 (19.4\%) participants had abnormal Visual Perceptual skill i.e.

scores less than 100 while $145(80.6 \%)$ had normal Visual Perceptual skill i.e. scores more than 100.

Table 3: Comparison of Age group \& Raw score

\begin{tabular}{|c|c|c|c|c|}
\hline Age group & $\mathbf{N}$ & Raw score & P value & Significance \\
\hline 6-6.11 yrs & 30 & $24.4+3.7(14-31)$ & \multirow[t]{6}{*}{$<0.001$} & \multirow[t]{6}{*}{ Significant } \\
\hline 7-7.11yrs & 30 & $26.7+3.1(21-33)$ & & \\
\hline 8-8.11 yrs & 30 & $30.2+4.1(22-38)$ & & \\
\hline 9- 9.11yrs & 30 & $31.4+3.7(21-41)$ & & \\
\hline 10-10.11 yrs & 30 & $33.4+3.9(22-40)$ & & \\
\hline 11-11.11 yrs & 30 & $34.3+3.6(27-42)$ & & \\
\hline
\end{tabular}

(One way ANOVA test)

Table 4: Bonferroni Post hoc comparison

\begin{tabular}{|c|c|c|c|}
\hline & & $P$ value & Significance \\
\hline \multirow[t]{5}{*}{ 6-6.11 yrs } & 7-7.11 yrs & 0.309 & Not significant \\
\hline & 8-8.11 yrs & $<0.001$ & Significant \\
\hline & 9-9.11 yrs & $<0.001$ & Significant \\
\hline & 10-10.11 yrs & $<0.001$ & Significant \\
\hline & 11-11.11 yrs & $<0.001$ & Significant \\
\hline \multirow[t]{4}{*}{ 7-7.11 yrs } & 8-8.11 yrs & 0.004 & Significant \\
\hline & 9-9.11 yrs & $<0.001$ & Significant \\
\hline & 10-10.11 yrs & $<0.001$ & Significant \\
\hline & 11-11.11 yrs & $<0.001$ & Significant \\
\hline \multirow[t]{3}{*}{ 8-8.11 yrs } & 9-9.11 yrs & 1.000 & Not significant \\
\hline & $10-10.11$ yrs & 0.019 & Significant \\
\hline & 11-11.11 yrs & $<0.001$ & Significant \\
\hline \multirow[t]{2}{*}{ 9-9.11 yrs } & 10-10.11 yrs & 0.669 & Not significant \\
\hline & 11-11.11 yrs & 0.042 & Significant \\
\hline 10-10.11 yrs & 11-11.11 yrs & 1.000 & Not significant \\
\hline
\end{tabular}


Figure 3: Comparison of Age group \& Raw score

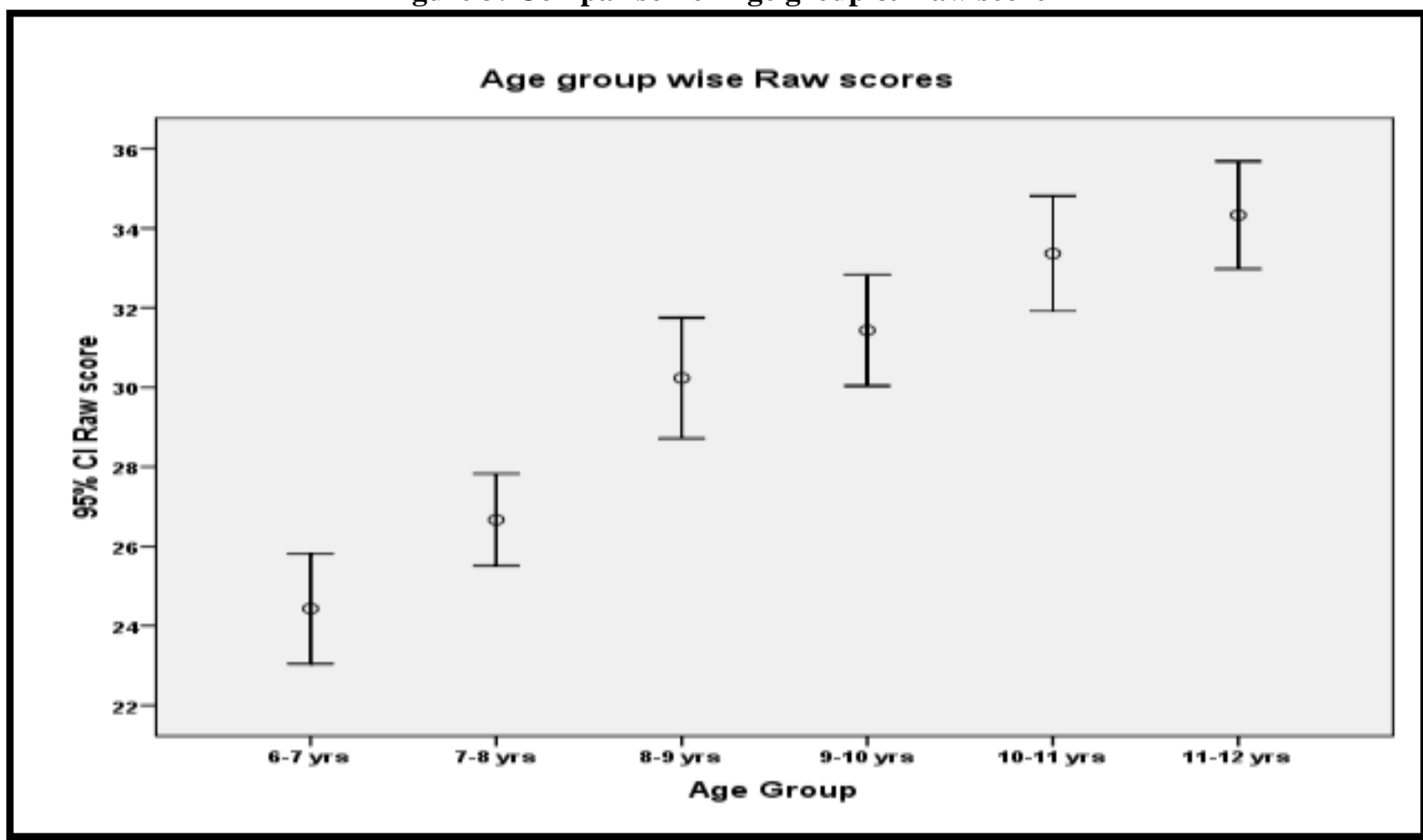

One-way ANOVA was done to compare the raw score of typically developing children in various age groups. The $P$ value was $<0.001$ which is highly significant. So further analysis of data was done using Bonferroni post hoc comparison. Performance of lower age group was compared with higher age group using unpaired t test, the $p$ value was 0.042 which is significant. There was significant difference in two groups. So, Bonferroni Post hoc comparison was done to find in group comparison between the groups. There was significant difference in 6-7 years and 7-8 years with all age groups. In 8-9years difference in all groups except for 9-10years, in 9-10 years all groups except 10-11years and for 10-11 years all groups except 11-12 years.

\section{DISCUSSION}

A comprehensive investigation into performance of typically developing (TD) children was done in the age group of 6 years to 12 years, using a standardized instrument named MVPT-4. This test is based on a sound theoretical framework that took into consideration development of visual perceptual skills among TD children ${ }^{(7)}$. A sample of $20 \%$ i.e. 180 children of the population calculated (900) from the pilot study was taken. Instead of conducting a large-scale survey, we relied on identifying TD children who met the inclusion criteria. To our knowledge this is the first study conducted to analyse the performance of TD children on MVPT-4 in India. These children's performance varied across the age groups.
The study had equal number of 30 TD children (table 3 and figure 2 ) in each age group (6 groups). Out of total sample $50 \%$ of the sample was male and remaining were female. Performance of Indian TD children showed a trend of increase in score as the child became older. This depicts the fact that age is related to maturity in visual perception skills. This finding is supported by the theoretical background of visual perception as described by Williams, he estimated the developmental ages for primary visual-perceptual skills development ${ }^{(8)}$. According to him, the development of most of the visual perceptual skills occurs around 7-9 years and then the skills further improve and refine as the child grows. The highest score obtained was by a child in age group 11, his raw score value was 42 with standard score of 137 and percentile of 99 . Whereas, the least score obtained was 14 by a $6 y$ r old with standard score of value 79 . Here, it is clearly evident that the age is an important factor for the augmentation of visual perceptual skills. Interestingly, highest standard score was 144 with raw score value of 41 and percentile rank >99 for a child of 9.06 years. This child had a good attention span, the child appeared focused and did not get distracted. He endured the entire test without any difficulty and answered confidently.

The mean raw scores showed positive trend as the age progressed. Apart from the maturation of the nervous system, children get wider exposure to the external world with progressing age as they grow. $\mathrm{He} / \mathrm{She}$ interacts with the environment and learns from the positive and negative experiences. This finding is supported by the author named Teresa 


\section{EPRA International Journal of Research and Development (IJRD)}

Farroni et al, the authors concluded that sensory experience from the external world can influence the way the brain wires itself up after birth; visual experience is crucial for a child's vision to develop normally-a "use it or lose it" situation $^{(9)}$. One important aspect of the current study is that MVPT-4 measures the different visual cognitive components. The observation that the different paradigms revealed different rates of development, with performance peaking at different ages, supports the proposal that these different aspects of visual attention rely upon different neural resources.

Also, as per the Acquisitional theory visual perceptual performance is influenced by our environmental experiences (Levine, 1987; Zimbardo, 1992). This development occurs through perceptual learning, the process of extracting information from the environment (4). Gibson (1969) noted, "Perceptual learning is defined as an increase in the ability of an organism to get information from its environments, as a result of practice with an array of stimulation provided by the environment",(10). This increases with experience and practice and through stimulation from the environment. The child is active in investigating the world, and any environment may encourage perceptual development (Piaget, 1964).

As seen in table 2, out of total sample of $180,145(80.6 \%)$ TD children performed $\geq 100$ standard score and $35(19.4 \%)$ TD children below 100 standard score performance. The children who performed more than 100 score did not do well in the test plates from 31-36 and 37-45. These needed greater concentration and demanded greater skills of visual perception. It will be interesting to note if the score on these tests improve with children in higher age group than 12 years. Test plate number 19 which seems to test visual perceptual skills like figure ground perception, form constancy, visual discrimination etc, was scored incorrect by maximum children. The children in older age group scored higher. Further, it was observed that out of these 145 children, the children in younger age did have difficulties in performing test item no. 31-36 and 3745 to the effect that they did not score any point most of the times in these items. As against the higher age group who scored more for these items. We observed, the children in the age group of 6 and 7 years, interpreted item number 5 differently. This item has 'coiled wire' like design. Option A, B and D had 3 loops in the coil, whereas option $C$ had 4 loops. Option $\mathrm{C}$ is the correct response. However, children in 6 and 7 age group seemed to concentrate on the orientation of the coiled wire and not on the number of loops. In option A, B and C the coil was placed in slanting orientation as against $\mathrm{D}$ where it was oriented horizontally. So, these children gave their response as option $\mathrm{D}$, which looked similar to the mother figure in orientation.

The study also brings forth the fact that there were 78 children in the study who performed above average -age equivalent scores and 15 children who performed below average - age equivalent score. Rest 87 children had average performance. Some characteristic behaviours observed in children who scored below 100 and around 100 standard score was that these children had a casual attitude in performing the test and completed the test in a hurry and were impatient to understand the example item of the subtests. As against them, the children who performed well, appeared cautious in choosing the response.

Interestingly, the developmental course of these basic VP components is highly variable depending on the level of difficulty, that is, the saliency of the difference to be perceived in each task. Item 1-3, item 10-13, item 28-30 seems competent to discriminate performance in the younger age group but appeared simpler for older children. On the other hand, item 14-18, item 31-36 and item $37-45$ present very subtle visual differences but children did not seem to perceive the difference and performed by chance. Finally, the items 4-9, and items 12-27 appeared to be the one that were the most sensitive to age differences from younger to older participants, giving a global picture of the developmental course of the VP processing components of interest. This finding is supported by Emilie Schmetz in the study: The processing of surface, length, orientation, and position. Her study results indicated that each level of difficulty (easy, medium, and hard) showed different sensitive periods of development at different ages with the exception of the hard level in the length and surface subtests which were performed at chance by all participants. These subtests therefore yielded no additional information about the development of the length and surface processing, in contrast to the easy and the medium levels of difficulty, which were useful to characterize the developmental trajectories of TD children $^{(11)}$.

Karen Lidzba et al studied dissociation of age with functional MRI in 43 healthy children and adolescents (7-17years). They found that as children grow there can be functional specialization which is inferred from an increase in focus and lateralization in higher as compared to lower age group children. Brain regions may become more functionally specialized with age ${ }^{(12)}$. In our study, we found younger group children had low performance and were less focused, fidgety and poorly endured the test as compared to older children. We can conclude with increase in age there is increase in activation of task- 


\section{SJIF Impact Factor 2021: 8.013| ISI I.F.Value:1.241| Journal DOI: 10.36713/epra2016 \\ EPRA International Journal of Research and Development (IJRD)}

Volume: 6 | Issue: 9 | September 2021

- Peer Reviewed Journal

specific areas of brain and decrease of activation in the areas less relevant for the task.

We further did one-way ANOVA (table 4) comparing the age and raw score analysing the difference in performance between the groups to find the subtle difference in age wise performance. TD children performance showed significant difference with $p$-value $<0.001$ (figure9). Hence, Bonferroni post hoc comparison was done (table 11) and significant difference was in 6-7 years, 7-8 years with all age groups. In 8-9 years, difference in all groups except for 9-10years, in 9-10 years all groups except 10-11years and for 10-11 years all groups except 11 12 years. The TD children performed better as the age progressed, this can be due to dissociation between two visual pathways which occurs with the age of the child. Vision for perception which allows recognition and identification of objects, people and natural scenes and is dependent on ventral, occipitotemporal pathway. While, vision for action, which allows visual guidance of actions, the analyses of visual guidance of action occurs through analysis of visual spatial information and visual motor planning, and depends on occipito-parietal pathway ${ }^{(13)}$. This network involved in the allocation of visuospatial attention matures progressively with age. The children in age group of 10-11 years and 11-12 years performed better than their younger counterparts in spatial relationship task.

\section{CONCLUSION}

From the above study we can conclude that MVPT-4 is a motor-free visual perceptual assessment tool which can assess the visual perceptual skills of Indian typically developing children in 6-12 years of age group. As the children grow the visual perceptual skills further refine and mature. Age impacts the performance based on the visual-perceptual skills.

\section{LIMITATIONS}

The limitations of this study were small sample size. The study was restricted to a particular geographical area. Available sample was collected from one centre, hence likely to have children from weaker socio-economic strata.

\section{RECOMMENDATION}

Study with larger sample size. Multicentre study for generalization of results

\section{REFERENCES}

1. Witt, J. C., Elliott, S. N., Gresham, F. M., \& Kramer, J. J. Glenview I. Assessment of special children: Tests and the problem-solving process. US Scott, Foresman Co. 1988;1. Witt, J.

2. Schneck CMC-S\& JO. Visual perceptual. J Occup Ther Child. 6th ed. 2010;373-403.
3. Schneck CM. Visual Perception. 6th edition. Mosby Elsevier; 2010. 373-403.

4. Kramer P, Hinojosa JIM. Frames of Reference for Pediatric Occupational Therapy. Third Edit. Bellus MS, editor. New York: Wolters Kluwer Lippincott Williams and Wilkins; 2010.

5. Chalfant, J.C. \&amp; Scheffelin, M.A, U.S. Department of Health education and welfare. Central processing dysfunctions in children: A review of the research: Phase three of a project. Bethesda, MD: US Dep Heal Educ Welf. 1969.

6. Ronald P. Colarusso DDH. Manual of Motor-Free Visual Perceptual Test-Fourth Edition (MVPT-4). Fourth. Frauwrith $S$, editor. Novato,CA: ATP Assessment; 2015.

7. Webster J. Typical and Not " Normal ". 2018;2017-8.

8. Williams H. Perceptual and motor development. Englewood Cliffs Prentice. 1983;NJ.

9. Terresa F, Kingdom U. Visual Perception and Early Brain Development. 2008;1-6

10. Brown T, Peres L. A critical review of the MotorFree Visual Perception Test - fourth edition ( MVPT-4 ) A critical review of the Motor-Free Visual Perception Test - fourth. J Occup Ther Sch Early Interv. 2018;11(2):229-44.

11. Schmetz E, Rousselle L, Ballaz C, Detraux J, Barisnikov K. BEVPS: A new test battery to assess visual perceptual and spatial processing abilities in 5-14 year-old in children BEVPS : A new test battery to assess visual perceptual and spatial processing abilities in $5-14$ year-old in children. 2016;0:0-17.

12. Lidzba K, Ebner K, Hauser T, Wilke M. Complex Visual Search in Children and Adolescents: Effects of Age and Performance on fMRI Activation. 2013;8(12):1-9.

13. Ziviani J, Copley J, Ownsworth TL, Campbell NE, Ziviani J, Copley J, et al. Visual Perception Abilities and Executive Functions in Children with School-Related Occupational Performance Difficulties Visual Perception Abilities and Executive Functions in Children with SchoolRelated Occupational Performance Difficulties. 2009; 1(3-4):246-262. 